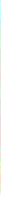

Artículo de reflexión E14A04 * Recibido: 30.10.2018. * Aprobado versión final: 5.11.2019. * JEL: M14, Q12, M10 * Pp. 119-136 * doi: 10.33571/teuken.v12n18a6

\title{
Importancia de la cultura organizacional para la gestión de las unidades económicas rurales.
}

\author{
Importance of the organizational culture \\ for the management of the rural economic units.
}

\author{
Evelia López Meza - Yolanda Sánchez Torres \\ María Dolores Martínez García \\ MÉJICO
}

\begin{abstract}
Resumen: para las empresas, la cultura organizacional es un factor determinante de éxito. Sin embargo, en las empresas rurales este elemento cobra mayor importancia al estar relacionado directamente con el origen de sus actividades productivas. La finalidad del presente documento es argumentar teórica y empíricamente sobre la importancia de la cultura organizacional en la empresa rural, mediante la revisión de estudios diversos, a partir de los cuales se proponen variables para el análisis de la cultura organizacional en este tipo de empresa. Existen factores externos, internos y de raíz; se argumenta que estos últimos son los más importantes, por ser parte de la herencia inmaterial y permiten el entendimiento de la organización. Se concluye que la cultura organizacional influye en la gestión de la empresa rural a nivel general.
\end{abstract}

Palabras Clave: cultura organizacional, empresa rural, gestión.

Abstract: For companies, the organizational culture is a determining factor of success. However, this element becomes more important for rural companies because it is directly related to the origin of their productive activities. The purpose of this document is to argue theoretically and empirically about the importance of organizational culture in rural enterprises through the review of several studies, which propose variables for the analysis of an organizational culture in this type of company. There are external, internal, and main factors of the organizational culture involved in the analysis, being the latter ones the most important as they are part of the intangible inheritance and allow the understanding of the organization. Finally, the paper concludes that the organizational culture influences the management of the rural enterprise.

Key Words: organizational culture, rural enterprise, management.

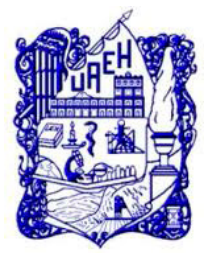

Evelia López M. es Licenciada en Comercio Exterior por la Universidad Autónoma del Estado de Hidalgo y estudiante de Maestría en Administración en la misma universidad, incorporada al Programa Nacional de Posgrados de Calidad (PNPC) de Conacyt. Instituto de Ciencias Económico Administrativas, UAEH - Méjico.

Contacto: evelia.Im@hotmail.com

Teuken Bidikay Vol. 12 № 18 (Medellín, Colombia) • Ene-Jun 2021. ISSN: 2215-8405 - e-ISSN 2619-1822. Pp. 119-136 


\section{Importância da cultura organizacional para a gestão das unidades econômicas rurais}

Resumo: para as empresas, a cultura organizacional é um fator determinante de sucesso. No entanto, nas empresas rurais esse elemento torna-se mais importante, pois está diretamente relacionado à origem de suas atividades produtivas. $\mathrm{O}$ objetivo deste documento é discutir teoricamente e empiricamente sobre a importância da cultura organizacional no empreendimento rural, por meio da revisão de diversos estudos, que propõem variáveis para a análise da cultura organizacional nesse tipo de empresa. Existem fatores externos, internos e radiculares; argumenta-se que estes últimos são os mais importantes, pois fazem parte da herança intangível e permitem a compreensão da organização. Concluise que a cultura organizacional influencia a gestão do empreendimento rural em nível geral.

Palavras-chave: cultura organizacional, empresa rural, gestão.

\section{Introducción}

E

I problema que aborda el estudio es la falta de valor que se da a la cultura organizacional en las empresas rurales, a pesar de considerarse un elemento clave para la gestión de este tipo de organizaciones. Si bien es cierto que existe una vasta información sobre estudios de la cultura organizacional, esta se focaliza principalmente en sectores económicos vinculados a la industria o al comercio, bajo la connotación formal de empresa; lo que es diferente para el sector primario, cuya figura organizacional para el caso de Méjico es la Unidad Económica Rural (UER). Las UER son agrupaciones de personas que en el medio rural se organizan para aprovechar los recursos naturales, los que conjuntamente están asociados a sus costumbres, tradiciones y condiciones territoriales (Gutiérrez, 2016, p. 124).

Si bien la cultura organizacional es sumamente importante para la gestión en general de todo tipo de empresas, es en el medio rural donde - por la propia naturaleza del territorio - impacta mucho más, ya que la valorización de la identidad cultural se observa fácilmente. Esto se debe a que en la mayoría de

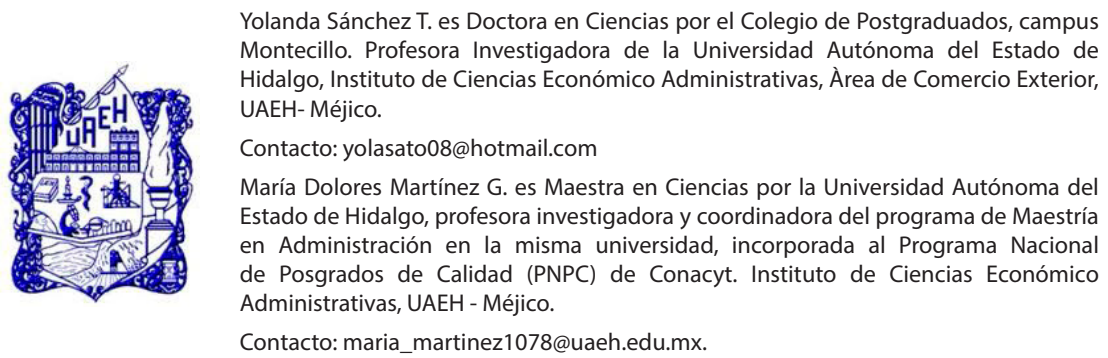


los territorios donde se establecen las organizaciones rurales productivas, el proceso de industrialización y globalización enfrenta una mayor resistencia y tiene un menor impacto, por lo tanto, conservan parte de su identidad. La pertenencia a cierto territorio los lleva a compartir una historia, los saberes, las costumbres, las normas, las formas de lenguaje, los símbolos y valores, y el territorio es parte de su 'patrimonio' para ser heredado a las siguientes generaciones (Fonte y Ranaboldo, 2007, p. 10).

Esimportante destacarque, en reiteradas ocasiones, a las unidades productoras que se localizan en el campo se les demerita su carácter de empresa; sin embargo, el aprovechamiento de los recursos del campo es considerado una actividad empresarial en diferentes marcos jurídicos, como en el caso de Méjico, donde de acuerdo con el Código Fiscal de la Federación párrafo tercero del artículo 16 (2016, p. 11), las unidades productoras se constituyen ante notario público especialmente como Sociedades de Producción Rural (SPR) (Ley Agraria, 2018, artículo 111). Su proceso productivo es respaldado por el régimen de actividad agrícola, de acuerdo con el segundo párrafo del artículo 74 de la Ley del Impuesto Sobre la Renta (LISR). Por lo tanto, además de estar legalmente constituidas, se consideran empresas rurales por estar ubicadas en un territorio de la misma naturaleza y por dedicarse al menos el 90\% a la actividad agrícola (LISR, 2016, p. 78).

Figura 1. PIB sectorial de Méjico para el último cuatrimestre de 2018

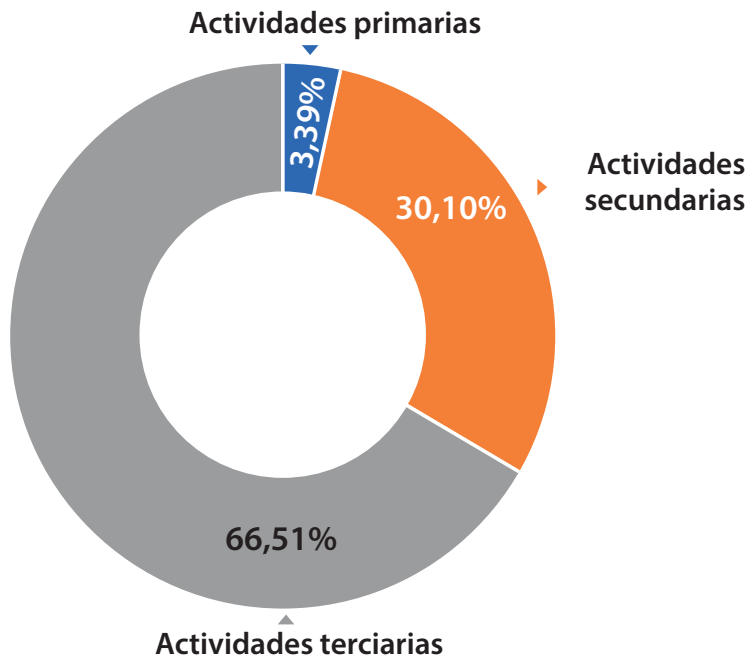

Fuente: Elaboración propia con datos de INEGI (2018)

Para comprender la dimensión de este tipo de empresa, vale señalar a manera de ejemplo que en Méjico existen —-según el último censo de 20075 millones 424 mil 430 UER (SADER, 2008), localizadas en el sector primario 
con una aportación al PIB nacional de 2008 de 3,34\% (INEGI, 2008), que ha aumentado a un 3,39\% en 2018 (INEGI, 2018), como se muestra en la Figura 1; y sobre todo representa una fuente de empleo para un número considerable de personas en el medio rural.

El objetivo del presente documento es hacer una revisión teórica sobre la conceptualización e importancia de la cultura organizacional de la empresa en general $y$, particularmente de la empresa rural, así como de estudios empíricos relacionados con dicha temática, que proporcionen una mayor argumentación sobre la relevancia y desagregación de los elementos que componen la cultura organizacional; de tal forma que ello permita una mejor gestión en general de las empresas rurales.

La revisión de estudios previos evidenció también que, si bien existen modelos para el estudio de la cultura organizacional, no hay uno en particular que permita el análisis de esta en la empresa rural y en general se tiene una escasez de estudios que aborden la temática. Por lo anterior, se propone abordar el tema con la consideración de distintos factores: externos, que alteran la conducta; internos, que la organización adopta, y los de raíz - los más importantes - que son en esencia los que la empresa tiene mediante sucesos históricos, generacionales y los valores de los fundadores. Con ello se podrá entender la trascendencia de este elemento para el fortalecimiento de la gestión de las empresas rurales y el desarrollo del entorno económico, social y ambiental.

\section{La cultura organizacional}

Para comprender la cultura organizacional es necesario remitirse al concepto de cultura en general, partiendo de que la cultura existe tras el reconocimiento de la existencia del ser humano mismo. Según la antropología, el ser humano es analizado en su relación con el entorno, en sus estados de conciencia e inconciencia, reflejados en su cultura, entendida como aquel conjunto de conocimientos, ideas, forma de vida, creencias, leyes y todo lo que los grupos humanos han heredado de sus antecesores. Aunque no existe un único concepto para la antropología o las ciencias sociales, lo que resulta cierto es que el humano es el único ser vivo que, por medio del lenguaje y otras habilidades, soluciona problemas, interpreta su entorno y forma organizaciones. Es un ser cultural porque construye la cultura por medio de la interacción con sus semejantes, formando con ello modelos organizacionales para su sociedad (Zapata y Rodríguez, 2008, pp. 18-25).

Como las personas son seres vivos capaz de organizarse, surge además la cultura dentro de la unidad de organización, o lo que es llamado la cultura organizacional. Esta tiene sus antecedentes en 1972 con los experimentos 
aplicados por Elton Mayo en Hawthorne, la fábrica más grande de Western Electric Co., que contaba con alrededor de 29 mil empleados. El objetivo del experimento fue comprobar los efectos favorables de una iluminación mejorada en la productividad individual. Sin embargo, con la contribución del notable antropólogo social W. Lloyd Warner y tras un extenso estudio se encontró que la productividad, más que relacionarse con condiciones físicas laborales, respondía más bien a las habilidades sociales y los comportamientos grupales, que tienen sus propios patrones de interacción a los que Mayo nombró "organización informal de los grupos" (2007, pp. 60-76).

A partir de la década de los ochenta se presentó una especie de boom en el estudio del tema, debido a que las organizaciones presentaron grandes cambios, especialmente en el marco de la competitividad internacional con la apertura de las economías (Dávila y Martínez, 1999, pp. 18-19). Con base en esto, la cultura organizacional se entiende como el conjunto de creencias, sentimientos y símbolos que caracterizan a una organización (Lunenburg, 2011 , p. 2), que dan sentido a las acciones y el comportamiento de las personas en la empresa, es decir, que se presentan como resultado de un proceso psicológico de los individuos. Con ello, las personas viven un proceso de adecuación cognitiva con los elementos de su realidad histórica y social (Serrate-Alfonso et al., 2014, p. 3).

Con base en el estudio de Alabart y Portuondo (2005, p. 2) puede decirse que existen innumerables definiciones de cultura organizacional que, si bien corresponden a las características propias de las organizaciones en un tiempo específico, estas se pueden agrupar en tres grupos. El primer grupo corresponde a la cultura organizacional en términos de 'símbolos, creencias y paradigmas'; el segundo se refiere a 'normas y valores' y el último incluye términos como 'filosofía, reglas, ambiente y presunciones'.

Los principales exponentes del primer grupo son Pettigrew, Smircich y Schein. Entre ellos, Pettigrew (1979, p. 574) fue el precursor del concepto de la cultura organizacional, y la definió como un sistema de términos, formas, categorías e imágenes aceptados colectivamente en un grupo, con los cuales interpretan las situaciones. Para Smircich (1983, p. 355), la idea sobre la cultura organizacional se enfoca en las cualidades expresivas y no racionales de la experiencia organizacional; y Schein (1984, p. 22) la explica como un patrón de suposiciones y paradigmas que manifiestan aspectos incomprensibles e irracionales de las organizaciones, donde las experiencias de aprendizaje compartido conducen a los miembros de la organización.

En consideración del objeto de estudio - la empresa rural- se retoma la conceptualización del primer grupo, dado que es justamente en ese espacio de tiempo que los autores estudiaron por primera vez la cultura 
organizacional partiendo de la cultura de los seres humanos en su territorio. La cultura organizacional en términos de símbolos y creencias es un elemento de fondo para la organización; la idea de cultura organizacional se enfoca en las cualidades expresivas y no racionales de la experiencia organizacional.

Para el análisis de la cultura organizacional en la empresa rural, se desagregan factores a partir de la revisión de estudios diversos sobre modelos para el estudio de esta temática. Autores como Smircich (1983, p. 355), quien hizo los primeros esfuerzos para explicar el vínculo entre organización y cultura, propuso un modelo de tres variables: externa, interna y de raíz. Un modelo similar es el de Schein (1984, p. 26), quien mostró que la cultura organizacional está dividida en tres niveles: 1) nivel visible que son los artefactos y las creencias, 2) nivel de conocimiento entendido como valores y creaciones y 3) suposiciones básicas, tales como aquellos hechos únicos que los integrantes de la empresa tienen de manera invisible.

Por otro lado, Thévenet (1992, pp. 15-27), utiliza un modelo dividido en tres niveles para explicar la cultura organizacional: 1) la cultura del medio en el que opera la empresa, en otras palabras, la cultura externa es el ambiente local y regional; 2) las subculturas de la empresa son grupos de personas no controlados por la organización y 3) la cultura de la empresa tomada como identidad en su totalidad, es decir, la empresa no tiene cultura, más bien es cultura.

Por su parte, Trompenaars y Hampden-Turner (2011) explican un modelo dividido en capas. La primera es la capa externa en la que se encuentra la cultura explícita, es decir, lo que se puede ver y prejuiciar; le sigue una capa media en la que se ubican las normas y los valores, y finalmente un núcleo que se refiere a la suposición de la propia existencia de la empresa, es decir, el actuar de las personas de forma inconsciente. Como puede verse, los modelos para el análisis de la cultura organizacional coinciden en la desagregación de tres grandes elementos; para Smircich son variables, para Schein y Thévenet son niveles, mientras que Trompenaars y Hampden-Turner dividen su modelo en capas. Esto permite concluir que, para el estudio de la cultura organizacional, pensando en la ruralidad, pueden estudiarse factores desagregados en tres grandes grupos: externos, internos y de raíz.

\section{Los factores organizacionales en las empresas rurales}

Como se ha mencionado, existen diferentes modelos para el estudio de la cultura organizacional, en los que se observa una desagregación similar de elementos. Sin embargo, para el presente estudio se consideran las aportaciones de Smircich, quien divide a las variables en externas, internas y la cultura como una metáfora raíz; además el aporte de Thévenet, quien determina factores externos y de identidad con los cuales especifica que 
la empresa es cultura y, finalmente, el trabajo de Trompenaars y HampdenTurner, quienes determinan las capas externa, media y nuclear. Se consideran todos estos porque hay similitud en la desagregación de los elementos para el análisis de la cultura organizacional, sean variables, niveles o capas, las concepciones de estos trabajos coinciden.

A pesar de que plantean la observación de ciertas variables, para el estudio de la empresa rural esto resulta más complejo. Es por ello por lo que se propone analizar la cultura organizacional a partir de variables: externas, internas y de raíz, ya que se pretende lograr un conocimiento del contexto territorial. Así, entonces, el objetivo en este apartado es argumentar teórica y empíricamente sobre las variables que proceden para observar la cultura organizacional en la empresa rural. Basados en las aportaciones de los autores arriba mencionados.

En la Figura 2 se plasma la desagregación de factores externos, internos y de raíz, para la conceptualización de la cultura organizacional en la empresa del medio rural, denominada en este caso unidad económica rural (UER), los cuales van a coadyuvar en la gestión de la organización.

Figura 2. Factores de la cultura organizacional para las UER

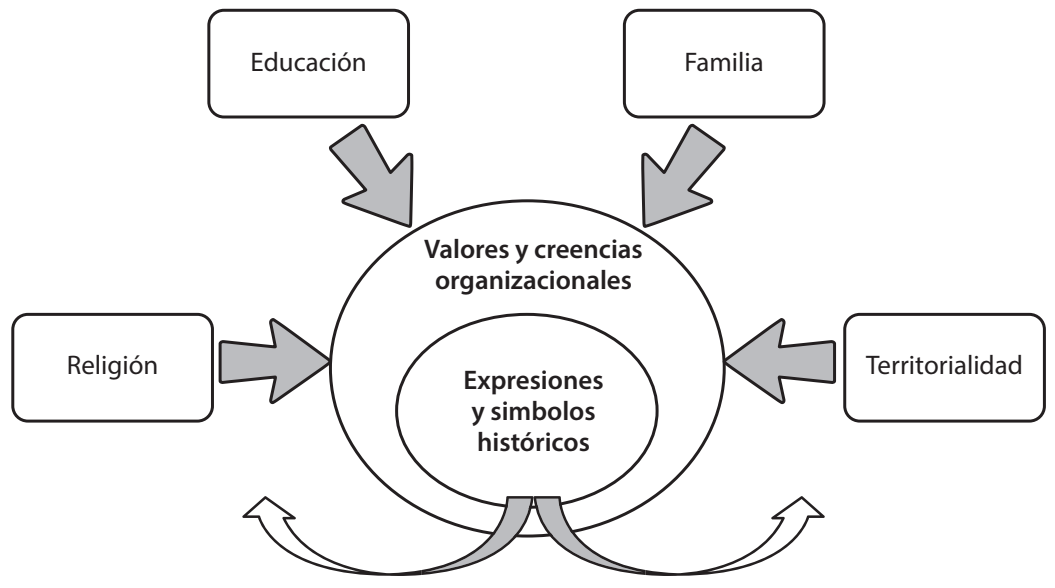

Fuente: Elaboración propia con base en Smircich (1983);

Trompenaars y Hampden-Turner (1997) y Muchnik (2006)

La Figura 2 esquematiza una propuesta para el estudio de la cultura organizacional, de acuerdo con los elementos señalados; pretende mostrar una interpretación sencilla de la interacción de factores que afectan el comportamiento cultural de las organizaciones rurales. Los factores ubicados dentro de los rectángulos son los externos, el círculo representa a la empresa rural y se encuentra dividido en dos niveles: el primero son los factores internos y el centro son los de raíz. 
Los factores externos se ubican fuera de la UER porque están en el entorno, pero afectan a la organización toda vez que esta los utiliza para definir su propia personalidad cultural, y se permean por medio de los empleados cuando entran en ella. Los valores y las creencias se crean dentro de la organización, pero no se encuentran en el círculo pequeño porque fueron adoptados por conveniencia. Los factores raíz se ponen justamente en el centro con proyección hacia afuera, porque van a la comunidad para formar parte de la caracterización de ese territorio; estos factores de raíz nacen de hechos históricos y valores de los fundadores que marcaron los aspectos simbólicos de la empresa.

\section{Factores Externos}

Para Smircich (1983, p. 343), los factores externos son aquellos que se encuentran en la sociedad y son introducidos a la empresa una vez que la persona ingresa a ella. Trompenaars y Hampden-Turner (1997), en su modelo de capas, se refieren a la primera capa externa como el conjunto de variables visibles, por medio de las cuales se crean los prejuicios de la unidad que se observa. Por esto, con base en el tipo de territorio que se analiza en este trabajo, se retoman las variables externas de García (2006, p. 165) que son: religión, educación, familia y comunidad'.

El factor religión fomenta una serie de valores profundos que guían a las personas y sus prácticas laborales e incluso puede ser fuente de conflicto entre individuos y naciones; por lo cual es evidente que dicho elemento toma cada vez más fuerza en las organizaciones (Edelberg, 2006, p. 136). Como referencia de estudios empíricos, Donatello (2011, pp. 37-52) identificó la lógica implícita de la relación entre la religión y la vida económica en Argentina, mediante entrevistas y relatos de trayectorias de empresarios y altos mandos de empresas afiliadas a la Asociación Cristiana de Dirigentes de Empresa (ACDE); los resultados arrojaron que existe un rol de la religión en la mentalidad y las acciones de los entrevistados. El autor comprobó que la relación de causalidad entre la empresa y la religión es positiva, pues las acciones de los empresarios muchas veces eran concebidas en el fondo por la religión, además de que el espacio socio-religioso se estableció como un lugar de construcción y reputación.

En la misma línea, Lee (2013, pp. 305-318) logró identificar, en su estudio exploratorio sobre la creencia en la Virgen María en empresas venezolanas, que en efecto la cultura organizacional se ve afectada por las creencias religiosas que residen en las personas, lo cual es un recurso que fortalece las 
relaciones humanas dentro de la organización. Particularmente en Méjico, la relación entre el trabajo y la religión se ha estudiado de forma secundaria; Galán y Martínez (2016, pp. 82-93) hicieron un esfuerzo por reflexionar las posibilidades heurísticas que permitieran abordar la religión y, a partir de un marco teórico-metodológico para conocer los conceptos de trabajo y religión de forma amplia, concluyeron que para abordar la relación entre religión y trabajo es necesario concebir este último como una relación social con la producción y no simplemente como una actividad de transformación, es decir, la religión y el trabajo se cohesionan en el mismo sistema social que funciona como una dinámica de retroalimentación.

Hicks (citado por Tristãoi y Oliver, 2007, p. 129) menciona que no existe un consenso sobre la definición de la religión dentro de la administración, puesto que se deben entender las diferentes realidades de la empresa. El factor religión es importante para la empresa rural, porque en la comunidad es un elemento que, además de dar personalidad a una colectividad, moldea algunos valores, normas y costumbres.

Otro factor externo es la familia, lo que se explica porque las empresas rurales suelen formarse a partir de esta. La familia se considera un eje básico para instruir la visión empresarial en los integrantes de la organización, por lo que se produce la fusión de dos instituciones: la familia y la empresa; algunos expertos han coincidido en afirmar que esto puede originar problemas, debido a que cada sistema tiene sus objetivos y prioridades distintas. En este contexto, lo que da respuesta a los conflictos es adoptar una cultura organizacional coherente con los valores familiares, como un elemento que cohesiona y forja las decisiones que se tomen respecto a la administración de la organización y cualquier filosofía (Steckerl, 2006, pp. 211-213).

Es en el seno familiar donde el individuo desarrolla actitudes, valores, conductas, ambiciones, la percepción de sí y la de los demás. La familia es un receptor de los cambios en el entorno y es una institución que se adapta a tales cambios para hacer que las personas sean capaces de actuar ante las contingencias e interrogantes de la vida (Ortega y Mínguez, 2003, pp. 41-42). En un estudio empírico, Steckerl (2006, pp. 195-215) demostró, por medio de un modelo explicativo de la empresa familiar, que los valores de la familia -específicamente del fundador - fueron clave para el fortalecimiento del liderazgo, y contribuyen a la continuidad generacional de la empresa familiar. Además, los valores familiares pueden consolidar económica y socialmente a la empresa, pues adquiere poder y reconocimiento.

Otro elemento que también puede ser considerado como un factor de cambio en toda organización rural es la educación, pues en las zonas rurales los niveles educativos no son tan altos cómo en las ciudades; sin 
embargo, las nuevas generaciones están actuando en la administración de las organizaciones de sus familias. En un estudio realizado en Ecuador en la comunidad rural de Otavalo, Célleri-Endara (2011, pp.13-16) demostró que los jóvenes rurales que tuvieron acceso a la educación volvieron a sus comunidades nativas para desempeñarse en puestos comunitarios; a pesar de haber migrado para buscar oportunidades laborales, mostraron un sentimiento de pertenencia que los llevó a renunciar a sus trabajos en las ciudades y aportar su conocimiento y habilidades a su comunidad natal.

Este factor es importante para el estudio de la empresa rural, porque no siempre se produce el arraigo de las personas educadas con su territorio, ya que los jóvenes rurales se encuentran en un proceso de transformación por su relación con la tecnología, la influencia de los medios de comunicación y la aproximación a las ciudades. Por ejemplo, en Méjico de Keijzer y Rodríguez (2003, pp. 1-24) realizaron un estudio en una comunidad en el sur del estado de Puebla y, por medio de observación participante y entrevistas, determinaron que la nueva generación de jóvenes del campo es muy diversa especialmente en el modo de inserción a la vida laboral; muchos de ellos migraron a la ciudad en busca de mejores oportunidades de empleo, pues el trabajo en las ciudades resultó ser más atractivo. La educación vista a través de la nueva generación de jóvenes rurales está teniendo un impacto en las organizaciones, ya que los actuales miembros de la empresa corren el riesgo de no tener a quien heredar tanto lo material como lo inmaterial.

El último factor externo es la territorialidad que, para García (2006, p. 165), es la comunidad; esta se refiere al espacio en el cual se relacionan comportamientos y actividades que dan forma al trabajo, lo que ofrece a los individuos un sentido de pertenencia, que se traduce en una serie de valores comunes que se desarrollan en la colectividad. Estos comportamientos son introducidos a la UER tal como los demás factores externos, que influyen en la adopción de una cultura y una filosofía organizacional, pues conviven en ese espacio común en el cual comparten modas y símbolos (Torres y Ramos, 2008, p. 89).

Al pensar en la empresa rural como una unidad única en relación con su territorio, se complementa este estudio con la interpretación de la territorialidad como elemento central del enfoque de los Sistemas Agroalimentarios Localizados (SIAL) (Muchnik, 2006, p. 13); incluso, con este enfoque, podría ser considerado en un momento dado como un factor raíz. El enfoque SIAL se refiere al estudio de territorios rurales de producción agropecuaria, por medio de la investigación e intervención; es una metodología de herramientas movibles y, para este caso, se utiliza como referente esencial para el estudio en la empresa rural. El objetivo principal de SIAL es valorizar el vínculo entre un producto y el territorio, por medio 
del reconocimiento de los recursos locales, el saber hacer y la cultura (GrassRamírez et al., 2016, p. 78).

Para los SIAL, el territorio representa el elemento central de su análisis, es el área históricamente unida y geográficamente concentrada y delimitada; los actores están particularmente interesados en la misma actividad y tienen un tipo de cooperación para el intercambio de conocimientos (Fourniery Muchnik, 2012, p. 133). En este sentido, se coincide en el concepto de territorialidad de los SIAL, ya que es su eje teórico central y se refiere a la conservación de un patrimonio territorial. El territorio se estudia en el SIAL a través de la dimensión histórica, pues en ella se observan las experiencias y la formación de las personas. Así, los lazos históricos generan un sentimiento de pertenencia que permite unir voluntades orientadas al desarrollo territorial; detrás de estos sentimientos, existen valores y códigos compartidos que se formaron en un proceso cultural, y es justamente por ellos que se institucionaliza un tipo de organización en un territorio (Muchnik, 2006, p. 18).

Las empresas rurales son formadas por personas de valores religiosos arraigados y por miembros de distintas generaciones de familias que conviven en una territorialidad; por lo tanto, estos elementos pueden ser los ideales para explicar la causalidad de una cultura organizacional en este tipo de organizaciones. Su relevancia reside en que ayuda a que los integrantes adopten los factores de forma ordenada y, en consecuencia, el alcance de los objetivos planteados por la empresa.

\section{Factores Internos}

De acuerdo con Smircich (1983, p. 344), los factores internos son los valores y las creencias propios que la organización establece por conveniencia, y pueden ser mitos, historias y lenguaje que sirven para su propio funcionamiento; podrían ser influenciados por los factores externos. Para Trompenaars y Hampden-Turner (1997), la capa media de su modelo son los valores y las normas; por lo tanto, al ajustar el modelo a la empresa rural, los valores y las creencias se consideran como factores internos. Estos también son mencionados por García (2006, p. 165), y se utilizan en el trabajo porque representan, de forma general y muy sencilla, los factores que las empresas rurales desarrollan una vez son influenciadas por el entorno. La organización los apropia como suyos, para fundamentar el comportamiento de las personas y justificar lo que es bueno o no para la organización.

En este sentido, una cultura organizacional sólida logra que los trabajadores estén comprometidos con los valores de la empresa, en caso contrario, cuando los valores no llegan a toda la organización, la cultura organizacional se fragmenta, tal como lo demostró Gerdhe (2012, p. 13), en su estudio empírico sobre las políticas que afectan las subculturas de la empresa Pro Credit Bank; 
en este, la relación entre los valores y la cultura es evidente y no se pueden entender de manera separada, pues están estrechamente relacionados con el actuar de los empleados.

Para Zapata (2002, p. 166), los valores son un elemento central de la cultura organizacional, ya que son percepciones que los miembros de la empresa construyen de acuerdo con situaciones, acciones y objetivos. Son fundamentales como elemento motivador del comportamiento (Zapata et al., 2009, p. 161). En un estudio de casos sobre tres empresas del nordeste de Méjico, y desde la teoría de sistemas, Garza et al. (2011, pp. 315-333) resaltaron que las empresas reconocen la importancia de los valores organizacionales provenientes especialmente del fundador, lo cual sugirió una influencia en el comportamiento de los empleados de las empresas de estudio.

Por otro lado, las creencias nacen de las historias y las anécdotas de la empresa $y$, de algún modo inevitable, crean convicciones colectivas que justifican comportamientos (Zapata, 2002, p. 173). Una cultura organizacional sólida, en la que los valores son reconocidos y apropiados por los integrantes de la organización, crea un ambiente armónico. Por ello la importancia de observar las variables internas para entender la cultura organizacional de la empresa rural.

\section{Factores Raíz}

La cultura organizacional, de acuerdo con Smircich (1983, p. 353) no es algo que la empresa tiene, sino más bien lo que es, como el alma de la empresa. En este sentido, se analiza no en términos económicos o materiales, sino más bien en sus aspectos expresivos y simbólicos. Thévenet (1992, pp.15-27), Schein (1984, p. 26) y Trompenaars y Hampden-Turner (1997) comulgan con este mismo principio y reconocen la existencia de un nivel de conciencia propia de la organización. En palabras de Aguirre (2002, p. 89), la empresa 'es' una cultura y no 'tiene' una cultura; es decir, no es un adjetivo, porque la cultura surge de la organización, en consecuencia, de un proceso de aprendizaje.

La cultura es la forma de interacción de un grupo de personas observado a lo largo de la historia, que es creada por estímulos heredados como la costumbre, la religión (factor que también es externo, aunque en este caso se trata del perfil de comportamiento que la religión formó en los fundadores), la tradición familiar, etc., es decir, experiencias de vida que enseñaron a las personas a interpretar el mundo. Por lo tanto, en la organización existe una negociación sobre esta percepción; de estas negociaciones surgen patrones de comportamiento que son institucionalizados como rutinas, normas o rituales, producto del pasado que les funciona en el presente (García, 2006, p.168).

Con base en lo anterior, se puede decir que las empresas rurales institucionalizan los símbolos y las creencias de quienes las constituyen, 
retroalimentando la propia cultura organizacional de su entorno (de ahí que en la Figura 2. se presente la dirección de las flechas hacia el exterior y en sentido ascendente). Entonces, el mantener una cultura organizacional fuerte y alineada con la naturaleza de la organización puede permitir incluso que un territorio mantenga y refuerce su personalidad. Por esto, se propone un esquema de retroalimentación, en el que la empresa rural sea un factor determinante de la cultura en una territorialidad.

Los factores raíz pueden ser los más importantes para la cultura organizacional de la empresa rural, puesto que incluyen la historia y los valores que profesan los fundadores, lo que es básico para que la empresa conserve su esencia, aún con el paso de generaciones. Los valores nacen de una familia que tiene la responsabilidad de dejar sólidas bases para que la organización perdure, así lo determinó Steckerl (2006, p. 211) con su estudio sobre la relación entre los valores del fundador de una empresa familiar y la cultura organizacional, quien reveló que el fundador busca un equilibrio entre la empresa y el bienestar familiar.

Otro estudio que destaca la importancia de los factores raíz para la cultura organizacional fue Gerdhe (2012, p. 11), quien logró demostrar que la cultura necesariamente está ligada a los valores de los miembros y que la comunicación de ellos es vital para lograr una cultura organizacional fuerte. Garza et al. (2011, pp. 315-333) también mostraron lo importantes que son los valores que el fundador hereda a la empresa; en su estudio, demostraron que los miembros de la organización reconocieron los valores del fundador, los que aumentaron su compromiso, así como estabilidad en su conducta.

Por lo anterior, se puede argumentar que los factores raíz son esenciales para el entendimiento de la cultura organizacional, desde un enfoque histórico y con base en los valores de los miembros fundadores. Estos elementos son los que logran que la organización trascienda a pesar del paso generacional. Por ello la importancia de poner atención a estos factores raíz, que determinan la cultura en una organización y, en consecuencia, la buena gestión de las organizaciones productivas que tengan lugar en estos territorios, como lo son las empresas rurales.

La fundamentación teórica y de estudios empíricos permite argumentar que la observación de factores externos, internos y raíz (Figura 2) puede contribuir considerablemente al entendimiento de la cultura organizacional en la empresa y particularmente de aquellas del medio rural, y enfatizar en los factores raíz, mediante la observación de la territorialidad como lo plantea el enfoque de los SIAL. 


\section{Importancia de la cultura organizacional en la empresa rural}

Como evidencia empírica de la importancia que tiene la cultura organizacional en empresas del sector rural, existen diferentes estudios empíricos, como el de Hernández y Prieto (2016, pp. 15-16), quienes realizaron un estudio sobre la cultura organizacional de dos cooperativas del sector agrícola en el Departamento del Atlántico en Colombia, con la metodología de observación participante. Los investigadores encontraron que las dos organizaciones reportaban carencia de liderazgo, procesos administrativos inapropiados, desconocimiento de la filosofía y poca motivación; lo que generaba una cultura organizacional débil $y$, en consecuencia, una baja competitividad y productividad. Concluyeron que el desarrollo y el fortalecimiento de la cultura organizacional permite un cambio de conducta, y recomendaron que se motive la participación y que se genere un ambiente interno próspero que propicie el empoderamiento.

En el estudio de Huertas (2005, p. 119) sobre la participación en una cooperativa rural de ahorro y crédito, por medio del reconocimiento de la cultura organizacional, se puntualizó que esta permite entender la lógica y las prácticas propias de la organización que le dan sentido a las acciones; por lo cual, la cultura se convirtió en un espacio de aspectos sociales articulados que además determina cómo las personas participan en la cooperativa.

Con un enfoque cuantitativo de orden correlacional, Gutiérrez (2016, pp. 119-136) desarrolló un estudio en 30 organizaciones productivas rurales colaborativas del municipio de Ameca en Jalisco, para determinar de qué manera la cultura organizacional, la cultura innovadora y el capital social inciden en el desarrollo de las organizaciones. Encontró que el capital social tenía una correlación mayor seguido de la cultura organizacional, en la cual los indicadores de estudio fueron: la planeación, la capacidad directiva y la adaptabilidad; además mostró cómo el factor cultura organizacional presentaba una relación directa con el éxito de las organizaciones, por lo cual propuso la necesidad de establecer relaciones interactivas e integradas para lograr las metas comunes.

Si bien son pocos los estudios que abordan la cultura organizacional en el medio rural, se puede ver cómo diferentes investigadores - con metodologías diversas - han coincidido en señalar que la cultura organizacional es un determinante importante para la gestión general de la empresa rural. Aunque esta aseveración podría ser la misma para cualquier tipo de empresa, se debe recordar que en las empresas rurales los factores culturales, además de ser más visibles, son arraigados; por lo que lograr un cambio de comportamiento es más complicado. Modelar la cultura organizacional ideal, coherente con las personas y al mismo tiempo alineada con los objetivos organizacionales, es 
un verdadero reto que de lograrse podría tener un efecto más profundo en esta tipología de organizaciones.

Por otro lado, las variables propuestas para el estudio de la cultura organizacional de la empresa rural podrían ayudar al entendimiento de la empresa, para tener una visión más amplia de las estrategias que se podrían tomar para fortalecer tanto la cultura como la propia gestión organizacional.

\section{Conclusiones}

A lo largo del documento, se han presentado una serie de conceptualizaciones y argumentos sobre diferentes variables que se podrían tomar en cuenta para el estudio de la cultura organizacional y la importancia de esta en la gestión de la empresa rural, englobadas en tres grandes categorías: factores externos, internos y de raíz; estos últimos como los más relevantes para la adopción de comportamientos en pro de la organización. La importancia de entender cómo se manifiesta y determina la cultura organizacional en las empresas rurales permite comprender la lógica de la conducta en las personas.

A pesar de la escasez de estudios sobre el tema de cultura organizacional en las organizaciones rurales, se considera que el esquema de retroalimentación de factores externos, internos y raíz puede ayudar a comprender mejor a la empresa, como aquella generadora de expresiones y símbolos, pues se considera apropiado y sencillo para entender la realidad de las empresas rurales.

Debido a que no existen modelos para el estudio de la cultura organizacional en la empresa rural, especialmente pensados en la ruralidad, se presenta la Figura 2, con la que se pretende coadyuvar al entendimiento visual sobre la trascendencia de los factores raíz para el funcionamiento de esta tipología de empresa; además permite entender cómo estos factores, al formar parte de una organización, se institucionalizan y modifican los aspectos simbólicos que la comunidad apropia y personaliza. Desde el enfoque territorial de los SIAL, la comunidad puede entenderse si se observa la cultura organizacional dentro de la empresa rural e, incluso, puede ser considerado como un elemento raíz.

Las empresas rurales forman parte de un territorio donde la cultura podría ser aliciente para su existencia y permanencia. Las personas que trabajan para estas organizaciones no se ven a sí mismas como empleadas, sino más bien como familia que desempeña una actividad históricamente importante que los representa. Entender la cultura organizacional en el medio rural, como un balance entre la comunidad, las familias, la religión y los valores intrínsecos de los miembros implica una perspectiva innovadora en su análisis. 


\section{Referencias bibliográficas}

1. Aguirre, S. (2002). La cultura de la empresa. Revista Subjetividades, 2(2), 86122. https://periodicos.unifor.br/rmes/article/view/1153/3429

2. Alabart, Y. y Potuondo, A. (2005). Propuesta metodológica para el diagnóstico de la cultura organizacional. Principales aplicaciones en el sector empresarial cubano. https:// www. monografias. com/t rabajos16/ diagnosticoorganizacional/ diagnostico-organizacional.shtml

3. Célleri-Endara, D. (2011). Latín-A: jóvenes indígenas (kichwa-otavalos) entre etnicidad, clase y género. Sapiens Research, 1(2), 13-16. https://www.srg.com. co/bcsr/index.php/bcsr/article/view/170/140

4. Código Fiscal de la Federación. (2016). Congreso General de los Estados Unidos Mejicanos. Reforma de 30 de noviembre de 2016. Diario Oficial de la Federación.

5. Dávila, A., y Martínez, N. (Eds.). (1999). Cultura en organizaciones latinas: elementos, injerencia y evidencia en los procesos organizacionales. Siglo XXI.

6. de Keijzer, B. y Rodríguez, G. (2003). Jóvenes rurales. Género y generación en un mundo cambiante. En Olavarría, J., (ed.). Varones Adolescentes: género, identidades: sexualidades en América Latina (33-51). FLACSO-Chile.

7. Donatello, L. (2011). ¿Secularización de la religión y sacralización de la empresa? Estudio de trayectorias de empresarios y altos gerentes católicos en la Argentina. Revista Argentina de Sociología, 8-9(15-16), 37-52. https:// www.redalyc.org/articulo.oa?id=26922386003

8. Edelberg, G. (2006). La espiritualidad y la religión en el trabajo. Revista Escuela de Administración de Negocios, (58), 135-140.

9. Fonte, M. y Ranaboldo, C. (2007). Desarrollo rural, territorios e identidades culturales. Perspectivas desde América latina y la Unión Europea. Revista Opera, (7), 9-32. http://www.redalyc.org/html/675/67500702/

10. Fournier, S. y Muchnik, J. (2012). El enfoque "SIAL" (Sistemas Agroalimentarios Localizados) y la activación de recursos territoriales. Agroalimentaria, 18(34), 133-144. http://www.redalyc.org/articulo.oa?id=199222712011

11. Galán, E. y Martínez, C. (2016). Religión y trabajo: acercamientos teóricos a una relación emergente. El Cotidiano (197). 82-93. https://www.redalyc.org/ articulo.oa?id=32545857011

12. García, C. (2006). Una aproximación al concepto de cultura organizacional. Universitas psychologica, 5(1), 163-174.

13. Garza, M., Medina, J., Cheín, N., Jiménez, K., Ayup, J., y Díaz, J. (2011). Los valores familiares y la empresa familiar en el Nordeste de México. Cuadernos de Administración, 24(42), 315-333. http://www.redalyc.org/articulo. oa?id=20520042015

14. Gerdhe, S. (2012). The policies that affect the extent of the Subcultures' Alignment in organization. Journal of Knowledge Management, Economics and Information Technology, (8), 1-19. 
15. Grass-Ramírez, J., Cervantes-Escoto, F., y Palacios-Rangel, M. (2016). Elementos metodológicos para el fortalecimiento del enfoque de sistemas agroalimentarios localizados (SIAL). Agricultura, sociedad y desarrollo, 13(1), 63-85.

16. Gutiérrez, S. (2016). Capital social, cultura organizacional, cultura innovadora y su incidencia en las Organizaciones Productivas Rurales Colaborativas. Economía y Sociedad, 20(34), 119-136.

17. Hernández, O. y Prieto, R. (2016). Cultura organizacional en cooperativas del sector agrícola - en el departamento del atlántico. En Ziritt, G. Diálogo de saberes desde las ciencias económicas, administrativas y contables (20-31). Cecar.

18. Huertas, O. (2005). La participación en una cooperativa rural de ahorro y crédito: un análisis desde la cultura organizacional. Cuadernos de Desarrollo Rural, 2(55), 97-121.

19. Instituto Nacional de Estadística y Geografía - INEGI (2008). Censo Agrícola, Ganadero y Forestal. Gobierno de Méjico.

20. Instituto Nacional de Estadística y Geografía - INEGI (2018). PIB y cuentas nacionales. Producto Interno Bruto Trimestral. Gobierno de Méjico.

21. Lee, C. (2013). Dimensión religiosa en las empresas familiares venezolanas. Espacio Abierto, 22(2), 305-318. https://www.redalyc.org/articulo. oa?id=12226914007

22. Ley Agraria. (2018). Reforma 25 de junio de 2018. Gobierno de Méjico.

23. Ley del Impuesto Sobre la Renta - LISR. (2016). Congreso General de los Estados Unidos Mejicanos. Reforma de 30 de noviembre de 2016. Diario Oficial de la Federación.

24. Lunenburg, F. (2011). Understanding Organizational Culture:A Key Leadership Asset. National forum of educational administration and supervision journal, 29(4), 1-12. http://www.curriculumandlearning.com

25. Mayo, E. (2007). The Social Problems of an Industrial Civilization. Routledge.

26. Muchnik, J. (2006). Sistemas agroalimentarios localizados: evolución del concepto y diversidad de situaciones [ponencia]. III Congreso Internacional de Ia Red SIAL. Baeza, España. http:// yal.agropolis.fr/ALTER06/pdf/actes/c14.pdf

27. Ortega, P., y Mínguez, R. (2003). Familia y transmisión de valores. Teoría de la Educación, 15, 33-56. https://gredos.usal.es/jspui/bitstream/10366/71937/1/ Familia_y_transmision_de_valores.pdf

28. Pettigrew, A. (1979). On Studying Organizational Cultures. Administrative Science Quarterly, 24(4), 570-581. http://www.jstor.org/stable/2392363

29. Schein, E. (1984). Coming to a New Awarenessos Organizational Culture. MIT Sloan Management Review, 3. https://sloanreview.mit.edu/article/coming-toa-new-awareness-of-organizational-culture/

30. Secretaría de Agricultura y Desarrollo Rural - SADER. (2008). Resultados de la Línea de Base 2008. Gobierno de Méjico. http://www.fao-evaluacion.org.mx/ cuestionario_final/indicadores_exp_2008/indicadores/ 
31. Serrate-Alfonso, A., Portuondo-Vélez, Á., Sánchez-Puigber, N. y SuárezOjeda R. (2014). Evaluación de la cultura organizacional y su incidencia en la efectividad grupal. Ingeniería Industrial, 35(1), 2-12. http://scielo.sld.cu/pdf/ rii/v35n1/rii02114.pdf

32. Smircich, L. (1983). Concepts of Culture Organizational Analysis. Administrative Science Quarterly, 28(3), 339-358. https://www.jstor.org/ stable/2392246?origin=crossref\&seq=1\#page_scan_tab_contents

33. Steckerl, V. (2006). Modelo explicativo de una empresa familiar que relaciona valores del fundador, cultura organizacional y orientación al mercado. Revista Pensamiento \& Gestión, (20), 194-215.

34. Thévenet, M. (1992). Auditoría de la cultura empresarial. Díaz de Santos S.A.

35. Torres, G. y Ramos, H. (2008). Gobernanza y territorios Notas para la implementación de políticas para el desarrollo. Revista Mexicana de Ciencias Políticas y Sociales, 50(203), 75-94.

36. Tristãoi, G. \& Olivier, M. (2007). Reseña de "Religion and The Workplace" de Douglas A. Hicks. Revista de Administração de Empresas, 47(3), 128-129.

37. Trompenaars F. \& Hampden-Turner, C. (1997). Riding the Waves of Culture: Understanding diversity in global business. Natl book network.

38. Trompenaars, F., \& Hampden-Turner, C. (2011). Riding the waves of culture: Understanding diversity in global business. Nicholas Brealey International.

39. Zapata, A. (2002). Paradigmas de la cultura organizacional. Cuadernos de Administración (27), 163-186. http://fayol.univalle.edu.co/Publicaciones/ pagina\%20web/Articulos/27-Cuadernos_de_Administarcion_ (Marzo-2002)/27-(06)_Paradigmas_de_la_cultura_organizacional_(Alvaro_ Zapata_Dominguez).pdf

40. Zapata, A. y Rodríguez, A. (2008). Cultura organizacional. Ediciones Universidad del Valle.

41. Zapata, A., Primero, L. y Arias, J. (2009). Cultura organizacional para la calidad total. En Encuentro nacional de investigación en administración (153-167). https://www.academia.edu/27960817/CULTURA_ORGANIZACIONAL_PARA_ LA_CALIDAD_TOTAL

\begin{tabular}{|c|l|}
\hline $\begin{array}{c}\text { Para citar } \\
\text { este artículo: }\end{array}$ & $\begin{array}{l}\text { López M., E., Sánchez T., Y. y Martínez G., M. D. (2021). Importancia de la } \\
\text { cultura organizacional para la gestión de las unidades económicas rurales. } \\
\text { Teuken Bidikay, 12(18), 119-136. doi: 10.33571/teuken.v12n18a6 }\end{array}$ \\
\hline
\end{tabular}

Ge*: AMV. 